\title{
EL SISTEMA DEFENSIVO DE LOS TERRITORIOS PRÓXIMOS A LA FRONTERA CON EL REINO DE FRAN- CIA EN TIEMPOS DE CARLOS V. UN DOCUMENTO INÉDITO DE LOS AÑOS CUARENTA DEL SIGLO XVI
}

\author{
Alfonso Franco Silva \\ Universidad de Cádiz
}

\section{$\underline{R E S U M E N}$}

En el contexto de la IV Guerra contra Francia (1541-1542), el Condestable de Castilla, Pedro Fernández de Velasco informa, a petición del Consejo de Castilla, sobre el estado de las defensas españolas. El presente artículo saca a la luz el citado informe, incluyendo la transcripción del documento.

Palabras clave: España, Siglo XVI, IV Guerra contra Francia.

\section{$\underline{A B S T R A C T}$}

In the mid-sixteenth century, during the fourth war among Spain and France (1541-1542), the Condestable of Castille, Pedro Fernández de Velasco, answered to Conseil of Castille over the state of presidium's fortifications and the disponibilited of the human and material recourses. This article transcribed and examined the document that has this information.

Keywords: Spain, $X V I^{\text {th }}$ century, Fourh War among Spain and France.

En el legajo 17, $\mathrm{n}^{\circ}$ 13, del Archivo Ducal de Frías encontré por casualidad un documento que de inmediato atrajo mi atención'. Tras leerlo detenidamente me di cuenta de que se trataba de un testimonio de interés excepcional para conocer cómo estaban organizadas las defensas de los territorios españoles que se hallaban relativamente próximos a la frontera francesa, tanto en lo que se refería al número de soldados, como en todo aquello que se estimaba fundamental para

\footnotetext{
' Fue catalogado en un primer inventario que se hizo de ese archivo, y que lleva por título índice General y Catálogos Parciales de los documentos que exisien en el Archivo Histórico de la Casa de Frías, que fue publicado en Madrid por el impresos José Góngora Alvarez en el año 1899. El Archivo Ducal de Frías que estuvo depositado durante muchos años en el pueblecito cordobés de Montemayor se encuentra hoy en Toledo, en concreto en el Archivo General de la Nobleza, una sección del Histórico Nacional.
} 
llevar a cabo una misión de esa importancia, tal como eran el estado en que se encontraba la artillería, las municiones y el armamento de que se disponía, y la forma en que estaban fortificadas las ciudades de San Sebastián, Logroño, Pamplona y Fuenterrabía. No cabía la menor duda, me hallaba ante un documento de gran valor, que además se encontraba inédito. Me decidí entonces a publicarlo, y no encontré otro medio más idóneo para ello que la revista Trocadero, en el número que dedica a la memoria de un excelente historiador y gran amigo, José Luis Pereira Iglesias, a quien previamente ya he dedicado un libro reciente a causa de la estrecha relación profesional y humana que nos unía.

\section{1.- Edición y análisis del documento}

De entrada tengo que decir que no soy, ni mucho menos, especialista en la historia militar del reinado de Carlos V, por consiguiente el análisis y comentario que del documento voy a tratar de hacer será por esa razón muy breve. En realidad, me voy a limitar a insertarlo en su contexto histórico -las guerras entre Carlos V y Francisco I- y, sobre todo, en el marco cronológico concreto en que debió redactarse, entre otras razones porque la única pretensión que me mueve al darlo a conocer no es más que aportar una pieza de gran valor para que pueda ser útil a los especialistas y estudiosos de esa época, y en concreto para aquellos que han orientado su investigación hacia temas relacionados con la organización del ejército español y sus continuos enfrentamientos con Francia a lo largo del siglo XVI.

Una lectura bien atenta del documento que publicamos nos muestra que en él hay dos partes bien diferenciadas. La primera parte es una instrucción que se envía a una alta personalidad, cuyo nombre no se indica, para que elaborase una completa relación del número de soldados que defendían los territorios del País Vasco, reino de Navarra y La Rioja de una posible invasión francesa, así como el estado en que se encontraba la artillería en esos lugares, y la forma en que se hallaban fortificadas Pamplona, Fuenterrabía, San Sebastián y Logroño, es decir las cuatro fortalezas más amenazadas por una eventual ofensiva de ese reino enemigo. La instrucción, ni en general todo el documento lleva fecha de expedición alguna, ni tampoco se dice qué alto organismo estatal - ¿posiblemente el Consejo de Estado?- la redacta, ni siquiera figura el nombre de la persona a quien se envía.

La segunda parte del documento se encuentra inserta inmediatamente después de la instrucción, de manera un tanto abrupta, porque comienza sin que, al parecer, la primera parte hubiese finalizado, al menos da esa sensación, porque la 
respuesta a lo que se demandaba se inicia al renglón siguiente en que finalizaba la citada instrucción. En realidad, nos encontramos ante un informe único que fue redactado por la alta personalidad a quien se dirigía la instrucción real, y en la que se decidió incluir esta última, a fin de que el organismo receptor tuviese constancia completa de aquello que solicitaba y de la respuesta detallada de lo que se le pedía. Así pues, esta segunda parte no es más que una relación exhaustiva del estado en que se hallaba la defensa de esos territorios, las carencias que se detectaban y las necesidades que se tenían. Es a no dudarlo la parte más rica e interesante de todo el documento.

Así pues, nos encontramos ante un testimonio excepcional por todo lo que contiene, que es mucho y de gran valor. Estamos de acuerdo desde luego, pero para comprender mejor la información que en él se recoge, y situarla en su adecuado contexto histórico, debemos preguntarnos por la fecha concreta en que fue redactado, porque, como ya dijimos, no figura en la relación. Sólo ella puede darnos la clave para entender mejor lo que se nos cuenta, pues hay que tener en cuenta que hubo cuatro guerras contra Francia en la época del Emperador. Sabemos, además, que ya se tenía amplia experiencia, al menos desde finales del siglo $\mathrm{XV}$, en pleno reinado de los Reyes Católicos, cuando se iniciaron las guerras contra Francia, de por donde podía producirse una invasión de la península: el País Vasco y Navarra eran los territorios más seguros. Así, cuando en 1521 comenzó la primera guerra contra Francisco I, los franceses invadieron el reino de Navarra -territorio por entonces poco seguro porque había sido conquistado por Castilla nueve años antes--, ocuparon con facilidad Pamplona, se situaron sobre Logroño, aunque no la pudieron conquistar, y finalmente en ese mismo año se apoderaron de Fuenterrabía ${ }^{2}$. A punto estuvieron de asediar San Sebastián, esa era la intención pero el mal tiempo lo impidión. La gravedad de la situación obligó a Carlos $\mathrm{V}$ a dirigirse a Burgos, a fin de poner orden en la artillería ${ }^{4}$. He aquí pues, la importancia que toman esas cuatro plazas -Pamplona, Logroño, Fuenterrabía y San Sebastián- como principales baluartes de la defensa no ya sólo de las Vascongadas, sino también de Navarra y del propio reino de Castilla. Aunque esas cuatro ciudades se recuperaron después, quedaba muy claro para los estrategas de Carlos V que había que tenerlas bien organizadas de todo tipo de bastimentos militares, y dotadas además de buenas fortificaciones, si se quería evitar en el futuro otra ofensiva francesa que pudiese ponerlas en peligro.

\footnotetext{
2 FERNÁNDEZ ÁLVAREZ, Mamuel, La España de Carlos V. Historia de España dirigida por Ramón Menéndez Pidal, Madrid, 1986, pp. 344-348.

${ }^{3}$ Ibidem, p. 348.

${ }^{4}$ A fines del año 1523 , Ibidem, p. 356.
} 
Queda bien patente que el informe que damos a conocer nada tiene que ver con la primera guerra contra Francia. Tampoco con la segunda, ni con la tercera, pues los principales escenarios de los combates, tanto de una como de la otra, tuvieron lugar muy lejos de los territorios antes citados. No tengo la menor duda de que el documento en cuestión fue redactado hacia el año 1542, cuando se iniciaba la cuarta guerra con los franceses, y se hallaba al mando de las tropas que defendían los territorios comprendidos entre el País Vasco y el reino de Navarra el cuarto condestable de Castila del poderoso linaje de los Velasco, don Pedro Fernández de Velascos. Lo afirmo de manera categórica porque en primer lugar el informe se encontraba entre los documentos oficiales del condestable, en segundo lugar porque la letra en que fue redactado corresponde plenamente a esos años, además de que otros testimonios personales del personaje están escritos en esa misma letra, $y$, por último, porque sabemos que fue don Pedro el encargado por el Emperador en esos años de organizar de la manera más eficaz posible el sistema defensivo respecto a los Pirineos occidentales, teniendo especial cuidado de defender tanto la región vasca como Navarra'. Las dos piezas claves para aquella defensa, según el profesor Fernández Álvarez, eran Fuenterrabía y Pamplona; de aquí que "para acudir a aquella que resultase amenazada, el condestable puso su cuartel en Vitoria"7. En esta cuarta guerra, según el citado Fernández Álvarez, los reinos de Castilla hicieron un enorme esfuerzo: se realizaron levas, se incrementó la producción de la pólvora y de la artillería, así como el aprovisionamiento de los principales presidios militares, se repartieron 4.500 soldados entre Pamplona, Fuenterrabía y San Sebastián, etc. ${ }^{8}$.

Así pues, es en el contexto de la cuarta guerra con Francia donde mejor puede insertarse la instrucción que probablemente recibió don Pedro Fernández de Velasco hacia 1541 o, todo lo más, en 1542 , y la relación de pertrechos militares que la acompaña como respuesta, y que, sin duda alguna, fue mandada redactar por ese aristócrata tras una amplia y exhaustiva información al respecto. ¿Qué se le pedía al condestable?. La instrucción que recibió le solicitaba que tuviese a bien informar sobre una serie de aspectos que interesaban a los conse-

\footnotetext{
"Ibídem, p. 691. Había sido ya Capitán General de Castilla en 1521, p. 345. Sobre este personaje las páginas que le dedico en "Los Condestables de Castilla y la renta de los diezmos de la mar", trabajo recogido en La Fortuna y el Poder, Servicio de Publicaciones de la Universidad de Cádiz, 1996, pp. $481-487$.

"lbídem, p. 691. Fernández Álvarez se basa a este respecto en la conocida Crónica de fray Prudencio de Sandoval, III, p. 126. Sobre esta guerra y, en general, todo lo relacionado con el conflicto francés son de un gran interés las páginas que le dedica KOHLER, Alfred Carlos V 1500-1558. Una biografia, E. Marcial Pons, Madrid 2000, p. 395-310.

Ibldem, p. 692.

"Ibidem, p. 699-701 y 711. Sobre la infantería y en general sobre las guerras del siglo XVI merece la pena la lectura de un delicioso libro de PUDDU, Raffaele, El Soldado Gentilhombre, E. ArgosVergara, Barcelona, 1984.
} 
jeros del monarca para conocer de forma confidencial el estado en que se encontraban las defensas militares de los territorios que tenía a su cargo. Estos eran los puntos principales:

- qué número de tropas de infantería había y cómo estaban organizadas, si habían recibido regularmente sus soldadas o no, y que capitanes que con ellas estaban acompañarían al Emperador en la campaña contra Francia, y quienes permanecerian en esos territorios para cuidar de su defensa

- así mismo se trataba de saber quienes eran los nobles que por el hecho de recibir acostamientos de la Corona deberían formar parte con sus propias huestes del ejército imperial, y aquellos otros que no podrían desplazarse de sus residencias por "justos enbaraços" - por alguna enfermedad probablemente-. En cualquier caso sería necesario, una vez que se supiese quienes eran y dónde vivían, que todos ellos, y en especial estos últimos, estuviesen preparados para salir al campo de batalla cuando se les ordenase

- de igual forma, los consejeros del Emperador querían saber qué número de caballeros y peones tenían a su disposición los corregidores que gobernaban las ciudades, es decir los efectivos humanos que en forma de milicias concejiles podrían aportar los municipios

- también se le pedía que informase acerca del número total de artilleros que había, así como los fundidores que allí se encontraban, quienes estaban encargados de la pólvora y cuantos maestros encargados de reparar los muros de las fortalezas tenía a su disposición

- finalmente se le ordenaba que describiese el estado en que se hallaban las fortificaciones de Pamplona, San Sebastián, Fuenterrabía y Logroño, qué artillería y pólvora había en cada una de ellas, y si había existencia de plomo en cantidad

El condestable quedaba obligado a redactar por escrito un informe detallado en el que se respondiese a todas y cada una de esas demandas. Pero, además, en el caso de que fuese vitalmente necesario que esas tropas a sus órdenes tuviesen que ser enviadas al campo de batalla francés, don Pedro tendría que hacer frente a toda una serie de preparativos que se detallaban minuciosamente en esa instrucción. Eran los siguientes:

- en primer lugar debía pedir que se trajesen de Flandes, con la mayor urgencia posible, picas, alabardas, arcabuces y escopetas; que, además se cortase mucha madera para las necesidades de la artillería, así como un número que estimase suficiente de jarcias de cáñamo, guindaletas, maromas, palos, picos y azadones 
- que tuviese preparados seis cañones serpentinos, dos culebrinas, doce medias culebrinas de treinta quintales cada una y doce falconetes de quince quintales cada uno. Se le pedía que acudiesen a Burgos fundidores de Málaga para que hiciesen fundir en sus hornos el cobre y el estaño, siempre que ese material estuviese disponible. Así mismo se le hacía saber que la exigencia de la madera era indispensable para construir ruedas y cureñas que sostuviesen los ingenios de la artillería

- que tuviese a su disposición pelotas para los seis cañones. Se calculaba que cada uno de ellos necesitaría unas 200 . En total 1.200 pelotas para los cañones, 600 para las culebrinas -300 para cada una-, 4.800 para las medias culebrinas -400 cada una- $y$ otras 4.500 para los falconetes

- debería de proveerse de bastante plomo, el preciso para abastecer arcabuces y escopetas

- que se concentrase la artillería en Burgos, a fin de saber qué númcro concreto de piezas habia y, en consecuencia, proveer aquello que faltase y fuese de gran necesidad

- finalmente se le pedia que mandase relación del número concreto de pelotas y coseletes que había en las fortalezas de Burgos, San Scbastián y Fuenterrabía.

El condestable Velasco, tras recibir la instrucción, se dispuso a responderla y a cumplir con todo aquello que se le exigía. Envió entonces al rey una relación completa de todas las piezas de artillería que se hallaban fuera de las fronteras del reino de Castilla, por si había necesidad de utilizarlas en caso de combate. La relación incluía también aquellas otras armas y piezas de artillería que pudiesen ser asi mismo necesarias y era preciso fabricarlas de nuevo, así como cl posible coste que podrián alcanzar cada una de ellas. Se describen así mismo todas aquellas piezas de artillería -cañones, culebrinas y falconetes-- que en caso de verdadera necesidad se podian desplazar de las ciudades y fortalezas de Logroño, Burgos, Simancas, Segovia, Madrid y Toledo para trasladarlas al campo de batalla francés. Además, incluía una relación de todas aquellas armas que, en opinión de don Pedro, en caso de verdadero peligro, se necesitarían para esa empresa militar, así como también las cantidades de dinero que scrían precisas para municiones, fundiciones de esas quince piezas, estaño, plomo, madera, azadones, picas, palas, carbón, el trabajo de los fundidores, etc.

El condestable trataba de organizar de la manera más rápida posible el abastecimiento y defensa de esas plazas militares, poniendo todas las medidas que fucsen precisas para ello, e incluyendo así mismo una relación de todo aquel armamento que, a su juicio, pudiese ser necesario para en caso de peligro des- 
plazarlo a los frentes de combate. Al final incluía en su informe una relación de todas las piezas de artillería que se hallaban en las ciudades y fortalezas de Pamplona, Fuenterrabía, San Sebastián, castillo de Beovia, la Torre del Pasaje, Burgos, Logroño, Estella, Toledo, Madrid, Segovia, Simancas y Tordesillas. Un informe, por tanto, muy completo y de un gran interés para el conocimiento de la historia de la artillería del reino castellano y, en general, para saber de una manera más precisa como se encontraban las defensas de las principales plazas militares que, en caso de guerra, podían ser fácilmente ocupadas por los franceses. 
S.f., s.1.

Instrucción encaminada a saver las gentes de armas, municiones, artillería y otros efectos de guerra y la forma en que estaban fortificadas Pamplona, Fuenterrabía, San Sebastián y Logroño, así como relación de toda la artillería que Carlos I poseía en Pamplona y frontera francesa.

A.- A.D.F., leg. 17/13.

Lo que se a de ablar es esto: qué gente de guardas ay y de dónde y cómo está repartida y cómo está pagada y qué capitanes van con su majestad y qué capitanes quedan acá, y que los que no fueren muy necesario que vayan con su majestad que queden acá y que escriban sobre ello. Si ay jente de acostamientos hablaran qu'es en lo que pueden seruir. Si ay otros caballeros o gente que en sus casas lleban dineros de su majestad, que no teniendo justos enbaraços para no salir d'ellas y no yendo agora con su majestad, que esten aperçeuidos para seruir quando los llamaren, y saver dónde son y dónde viben para saver a donde los an de ynviar a llamar quando fuere menester. Saver qué gente ordinaria ay de infanteria y cómo está pagada. Saver de los corregidores qué gente de cavallo y de pie ay o tiene cada çiudad y villa del reyno, saver qué capitanes de ynfanteria ay de los que estan sin gente y los que van con su magestad y los que quedan acá, y los que quedaren que esten aperçeuidos para quando les mandaren hazer gente. Saver qué maestro o maestros ay de reparos, saver quien queda con el artilleria y qué artilleros ay y qué fundidores y qué polboristas, saver cómo estan fortificadas Pamplona, Fonterrauia y San Sebastian y Logronno y lo que falta por hazer (fol.

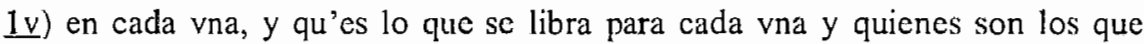
entienden en cada labor d'estas. Saver qué artilleria y polbora y otra muniçion ay en cada vno d'estos lugares. Que se fundan scis medios cannones de hasta quarenta quintales, y doze medias colebrinas de a veinte y çinco quintales, y veinte y quatro falconetes de a doze quintales, y que vengan a fundir esta artileria a la fortaleza de Burgos maestre Pedro el que está en Málaga. Saver qué polbora ay de respeto (sic) y si no la ay que aya vna buena cantidad d'ella, y que demás de la que estubiere hecha aya materiales para hazella. Que aya plomo en cantidad. Que se traygan picas y alabardas y arcabuzes y escopetas de Flandes. Que esté cortada mucha madera para encabalgar el artillería. Que aya mucha jarçia de cannamo, de guindaletas, maromas y otras cosas. Que aya palos y picos y açadones que esten de respeto con el artilleria. Que se sostenga lo del dinero de respeto.

Lo que se a de mandar prober para en caso que fuese menester salir con exerçito en canpo para el artilleria y cosas d'ella:

Proverse que aya seis cannones serpentinos de respeto en la casa de la muniçion de Burgos, dos culebrinas, doze medias culebrinas de a treinta quintales cada 
vna, (fol. 2r r) doze falconetes de a quinze quintales cada vno, que para la artilleria que d'esta no viere que se provea luego de cobre y estanno para que se pueda fundir en Burgos.

Que porqu'el tiempo que se perdiese haria mucha falta que dende luego se mande venir los fundidores de Malaga, para que en tanto qu'el cobre y estanno se trae los dichos fundidores hagan sus hornos y los moldes para lo que faltare de la dicha artilleria que se aya de fundir.

Porque para el artilleria que d'esta se oviere de fundir an menester de se encabalgar en ruedas y cureñas, y es menester que aya maderas secas que se manden cortar y labrar para que al tienpo que se oviere fundido aya recabdo para se encabalgar.

Que se provea que aya pelotas para los seis cannones serpentinos que es menester, a lo menos para cada vno dosientas pelotas que son mill y doçientas pelotas. Ansimismo para las culebrinas seisçientas pelotas, para cada vna trezientas, para las medias culebrinas quatro mill y ochoçientas pelotas, para cada vna pieça quatroçientas. Para los falconetes quatro mill ochoçientas pelotas, para cada vno quatroçientas.

Ansimismo prover de cantidad de plomo porque es nezesario que se provea de mucho para arcavuzes y escopeteros, porque se an de prover todos de lo que oviere en el artilleria. (fol. $2 \mathrm{v}$ ). Aya lugar de se rezibir otros tantos artilleros como su magestad mandó llebar, pues en la consulta que se hizo mandó que se reçiviesen otros tantos, y sin alargarse la consignaçion aquella cantidad que se tenía no se podian reçivir los artilleros de los quales ay neçesidad de se reçevir, porque los que ay están en Panplona y en Fuenterravia y en Gibraltar y en caso que oviese nezesidad no se podrian sacar de donde estan.

Que para las fundiçiones y para los otros gastos y xarçia y otras cosas es menester prover de dineros y para las otras cosas de menudençias que despues seran menester comprar.

Que la artilleria que ay que se a de sacar de los lugares donde agora está se mande sacar luego y se junte en Burgos, porque junta se pueda ver la que falta y que aquella se funda.

Que se provea que aya tiendas de respeto para en que esten la polbora y muniçiones del artilleria. 
Que se provea de coseletes sy no los ay para la ynfanteria y los que oviere se linpien y aderezen.

En Burgos ay dos mil y seiçientos coseletes.

En San Sebastian ay mill y seiçientos coseletes.

En Fuenterravia ay seisçientos y çinquenta coseletes.

\section{Pelotas}

En Fuenterravia dos mill y quinientos y setenta y quatro pelotas de cannon, dos mill y doçientas pelotas de culebrina, (fol. $3 \mathrm{r}$ ) dos mill y doçientas y siete pelotas de medias culebrinas, mill y quatroçientas y çinquenta y tres pelotas de falconetes.

En San Sebastian mill y quarenta pelotas de cannon mill y çient y sesenta pelotas de medias culevrinas, quatro mill y quatroçientas y ochenta y quatro pelotas de falconetes.

En Burgos mill y çien pelotas de falconetes de fierro, dos mill y sieteçientas pelotas de falconetes de plomo.

Las cosas que se mandaron prover son las siguientes: Quese fundieren diez medias culebrinas de a treynta quintales cada vna, mis çinco falconetes de a quinze quintales cada vno, que se enviasen a comprar a Vilbao quatroçientos quintales de cobre.

(En el margen izquierdo): Que se escriva a Juan Martinez de Ricalde y se le envie dineros.

Que se comprasen quarenta quintales de estanno para liga.

Que se comprasen treçientos quintales de plomo.

Que se mandasen fundir pelotas para los cannones y medias culebrinas y falconetes y culebrinas.

Que se mandasen hazer arcabuzes en cantidad. 
Que se mandasen fazer picas de fresno. Que se hiziesen palas y açadones y picos, que se cortasen maderas para las curennas y ruedas.

(En el margen izquierdo): Que daran dineros para ello.

Que se comprase hierro y ferraje para las guarniciones.

(En el margen izquierdo): Que daran dinero para ello y den el yerro. (fol. $3 \mathrm{v}$ ) Que se comprase çufre.

Que se enviase el salitre todo lo que más pudiese ser. (En el margen izquierdo): Çedula para que se envie.

Que viniesen maestre Pedro y Diego Garçia de Málaga a Burgos.

(En el margen izquierdo): Çedula para que vengan.

Los polboristas que bayan a Burgos aderezar los molinos. (En el margen izquierdo): Que se les mandará.

Que venga el mayordomo Françisco de Xerez a Burgos. (En el margen izquierdo): Cedula para el mayordomo.

Que Pedro del Peso visite los coseletes de Burgos y Fuenterrauia y San Sebastian.

Ansimismo vea Pedro del Peso las pelotas que ay en Fuenterrauia y San Sebastian para que quedando providas las villas vea las que se podran sacar y de que condiçion son.

En otro pliego ba aparte relaçion de toda el artilleria que vuestra magestad tiene en sus fronteras y en otras partes d'estos reynos, aquí solamente se pornán las pieças que ay fuera de las fronteras para poderse seruir d'ellas en caso que vuiese nezesidad de salier en canpo, y asimismo las que converná que vuestra magestad mande hazer de nuevo para que aya entero recaudo y lo que aquellas podran costar.

De Logronno se podran sacar dos medias culebrinas y dos falconetes de las pieças que alli estan para seruir en esto. En Burgos ay vna culebrina de las de Alemanna y vn cannon serpentino y otro pedrero que podran seruir.

Asimismo ay en Burgos tres falconetes, en Simancas ay vn cannon pedrero y vna culebrina que podrán seruir. 
En Segouia ay vn cannon serpentino y vn falconete que podrán seruir.

(fol.4r) En Madrid ay dos cannones serpentinos y dos falconetes que podrán seruir.

En Toledo dos cannones, los quales son menester fundir por respeto de no tener razon de pelotas ni metal.

Sacandose toda esta artilleria de donde está faltaria para el entero recaudo de lo que es menester para salir en canpo lo siguiente:

Diez medias culebrinas, que para ellas son menester doçientas y çinquenta quintales de mental, montaria a seis ducados y medio el quintal ........ I (mil) DCXXV ducados.

Cinco falconetes, y para ellos ochenta quintales de metal que a razón de los dichos seis ducados y medio el quintal montaria quinientos y çinquenta ducados DL ducados.

Para las fundiçiones d'estas quinze pieças que a razón de castellano por quintal y más las costas de horno y animas y otras cosas mill y quatroçientas ........ I (mil) CCCC ducados.

Para encabalgar y adereçar esta artilleria y poner en horden la que se houiere de sacar de las partes que aquí ban nonbradas siendo vuestra magestad seruido porque sinon se vbiese de sacar conuernia que vuestra magestad lo proveyse mill ducados I (mil) ducados.

Para pelotas, xarçia, plomo y otras muniçiones tres mil ducados lII (mil) ducados.

A Juan Martinez de Recalde se le enviaron mill ducados para que conprase los quatroçientos quintales de metal y quarenta de estanno para el artilleria.

Está despachada çedula para que se den otros (fol. 4v) mill al pagador del artilleria para comprar madera, plomo, açadones, picas, palas, carbon y para guarneçer los cartones y curennas. Despachóse çedula para que maestre Pedro fundidor y Diego Garçia vengan luego a Burgos para hazer los moldes y fundiçion de artilleria.

Escriuiose a Sancho Martinez que hiziese poner la media culevrina que se acordó en la torre del pasaje. 
Despachóse çedula para que Montalbo envie todo el salitre del Prioradgo y Tenble y Pedernoso, en lo de las pelotas y arcabuzes se toma çierto asiento con Anton de Vrquicu.

Relaçion del artilleria que su magestad tiene en Panplona y en sus fronteras es lo siguiente:

Fortaleza de Panplona:

- vna culebrina cruzada

- vn cannon franzes

I culebrina

- quatro medias culebrinas

I cannon

- quatro falconetes

IIII medias cuIebrinas

- seis ribadoquines

IIII falconetes

- çiento y setenta arcabuzes

VI

ribadoquines

- çiento y çinquenta escopetas

CLXX arcabuzes

CL escopetas

La çiudad de Panplona:

- çinco canones serpentinos

V cannones

- dos culevrinas

II culevrinas

- seis medias culevrinas

VI

medias culevrinas

- ocho falconetes

VIII

falconetes

- çiento y setenta y nueve arcabuzes de yerroen sus bancos

CLXXIX

arcabuzes

- seyscientas y veinte y seis escopetas

DCXXVI escopetas

Fuenterrauia:

- dos culevrinas

II

culevrinas

- dos medios cannones

II cannones

(En el margen izquierdo): Llevaron estos dos cannones a la armada de su magestad.

- seis cannones

- vn cannon pedrero

- tres medias culevrinas

VI

I

III cannones cannon pedrero

culevrinas 
- dos sacres

II

sacres

- honze falconetes

XI

falconetes

- vn esmeril

esmeril

- çinco arcabuzes

V

arcabuzes

- vn cannon de yerro

I

cannon

- ocho rivadoquines de yerro

VIII

ribadoquines

- doçientas y noventa y seis arcabuzes de yerro

CCXCVI

arcabuzes

- çiento y setenta y çinco escopetas

CLXXV

escopetas

San Sevastian:

- quatro cannones serpentinos

IIII

cannones

- vn canon pedrero

I

canon

- vna culevrina

- çinco medias culevrinas

I

culevrina

- dos sacres

V

medias culcrrinas

- çinco falconetes

Il

sacres

- çiento y ochenta y siete

arcabuzes de garavato

CLXXXVII

arcabuzes

- setenta y siete arcabuzes de manno

LXXVII

arcabuzes

- treçientas y sesenta y

nueve escopetas

CCCLXIX

escopetas

(En el margen izq.): Demas d'esta artilleria ay en San Sevastian dos seruidores de dos lonbardas de la nao Angela que se quemó que podian pesar çinquenta quintales.

La Torre del Pasaje:

- dos falconetes

falconetes

En el castillo de Veovia:

- media culevrina

$\begin{array}{cl}\text { media } & \text { media culevrina } \\ \text { I } & \text { sacre } \\ \text { I } & \text { falconete } \\ \text { I } & \text { ribadoquin } \\ \text { VI } & \text { arcabuzes }\end{array}$

- vn sacre

- vn falconete

- vn ribadoquin

- seis arcabuzes

arcabuzes 
Burgos:

- dos cannones grandes de Tornay

II

cannones

- quatro cannones dobles que tiran pelota de ochenta

IIII

cannones dobles

- vn cannon doble que tira pelota de fuego I

cannon

(En el margen izquierdo): Estos siete cannones son tan cargados que no se pueden seruir d'ellos sin mucho enbaraço.

- vna culebrina

- vn cannon serpentino castellano

- vn cannon pedrero

- tres falconetes

- dos morteretes

- treçientos y treinta arcabuzes

- doçientas y veinte y quatro escopetas

En Logronno:

- dos medios cannones

- dos medias culevinas

- quatro falconetes

Estella:

- vn cannon serpentino

- vn sacre

- vn falconete

- dos ribadoquines

- dos arcabuzes de metal

- treinta escopetas

En Toledo:

- dos cannones grandes

En Madrid:

- dos cannones serpentinos

- dos falconetes

$\begin{array}{cl}\text { I } & \text { culevrina } \\ \text { I } & \text { cannon serpentino } \\ 1 & \text { cannon } \\ \text { IIII } & \text { falconetes } \\ \text { II } & \text { morteretes } \\ \text { CCCXXX } & \text { arcabuzes } \\ \text { CCXXIIII } & \text { escopetas }\end{array}$

II

II

medios cannones

IIII

medias culevrinas

falconetes

cannon

sacre

falconete

ribadoquines

arcabuzes

escopetas

II cannones 
En Segovia:

- vn cannon serpentino

I cannon

- vn falconete

I falconete

Simancas:

- vna culevrina

I culevrina

- vn cannon pedrero

I cannon

- seis falconetes pequennos

VI falconetes

En Tordesillas:

- dos falconetes

II

falconetes 